\title{
COMPARISON BETWEEN TAMSULOSIN AND SILODOSIN IN LOWER URETERIC STONE- A RANDOMISED CONTROLLED STUDY
}

\author{
Priyanka1, Ravikumar R. Jadhav²
}

1 Resident, Department of Surgery, KIMS, Hubli.

${ }^{2}$ Associate Professor, Department of Urology, KIMS, Hubli.

\begin{tabular}{l}
\hline ABSTRACT \\
BACKGROUND \\
$70 \%$ of ureteral stones are located in the lower third of the ureter. Medical expulsive therapy (MET) using adrenergic antagonists \\
has recently emerged as an alternative strategy for the initial management of small distal ureteral stones. We planned a study to \\
compare the efficacy of silodosin $8 \mathrm{mg} /$ day with tamsulosin $0.4 \mathrm{mg} /$ day with respect to stone expulsion time and stone expulsion \\
rate.
\end{tabular}

\section{MATERIALS AND METHODS}

A randomised controlled study was carried out on 70 cases having distal ureteric stones (DUS) of size $\leq 10 \mathrm{~mm}$. All cases were above 20 years of age. 35 patients received single dose of tamsulosin $0.4 \mathrm{mg} /$ day and 35 patients received single dose of silodosin $8 \mathrm{mg} /$ day. Patients were followed by ultrasonography till stones were passed or upto 4 weeks after initiation of medical expulsive therapy.

\section{RESULTS}

15 out of 27 cases in group tamsulosin and 23 out of 28 cases in group silodosin expelled the stones by the end of study. The mean time of expulsion in tamsulosin group was $19.1 \pm 8.6$ days, while silodosin group was $16.7 \pm 6.8$ days. The difference between tamsulosin and silodosin group did not reach statistical significance. The expulsion rate in tamsulosin group was $55.5 \%$ and silodosin group was $82.1 \%$, which had statistical significance. The outcome of silodosin and tamsulosin was found to be not affected by the gender of patients. Silodosin is more effective in patients with distal ureteric calculi $>7 \mathrm{~mm}$.

\section{CONCLUSION}

Silodosin was found to be more effectual than tamsulosin in terms of stone expulsion rate and stone expulsion time for the management of distal ureteric stones of size $\leq 10 \mathrm{~mm}$.

\section{KEYWORDS}

Distal Ureteric Stones, Silodosin, Tamsulosin, Stone Expulsion Rate, Stone Expulsion Time.

HOW TO CITE THIS ARTICLE: Priyanka, Jadhav RR. Comparison between tamsulosin and silodosin in lower ureteric stone- a randomised controlled study. J. Evolution Med. Dent. Sci. 2017;6(93):6766-6769, DOI: 10.14260/jemds/2017/1465

\section{BACKGROUND}

The life-time risk of developing urinary calculi is between $5 \%$ to $12 \%$, affecting men more than women.[1] The rate of spontaneous passage with no medical intervention for a stone of $5 \mathrm{~mm}$ or smaller in the proximal ureter is estimated to be $29 \%$ to $98 \%$, and in the distal ureter to be $71 \%$ to $98 \%{ }^{[2]}$ In recent years, there has been a growing trend in administering medication in addition to analgesia to patients with distal ureteric calculi in order to help with the expulsion of a calculus. ${ }^{[3]}$ Medical expulsion therapy (MET) has recently emerged as an appealing option for the initial management of ureteral stones. ${ }^{[4]}$ There is a large body of published data, which has shown the efficacy of such a therapy in increasing the expulsion rate and in decreasing the expulsion time of the stones.[5-7] Tamsulosin, an $\alpha_{1}$-adrenoceptor antagonist, is uroselective for $\alpha_{1 \mathrm{~A}}$ and $\alpha_{1 \mathrm{D}}$ receptors. This is a very popular and effective medical agent used for Medical Expulsive

'Financial or Other Competing Interest': None.

Submission 18-07-2017, Peer Review 20-11-2017,

Acceptance 27-11-2017, Published 11-12-2017.

Corresponding Author:

Dr. Ravikumar R. Jadhav,

Associate Professor

Department of Urology,

KIMS, Hubli.

E-mail: jadhavsurgeon@yahoo.co.in

DOI: $10.14260 /$ jemds $/ 2017 / 1465$

\section{(c) (i) $(5)$}

Therapy (MET). But, recently it has been reported that the $\alpha_{1 \mathrm{~A}}$ adrenoceptor is the main participant in phenylephrineinduced ureteral contraction in human isolated ureter. ${ }^{[8]} \mathrm{A}$ newly introduced drug silodosin, more of an $\alpha_{1 \mathrm{~A}}$ selective adrenoceptor antagonist has shown promising results with fewer side effects and better efficacy. The use of these drugs in the treatment of distal ureteral stones arose from the concept that they could induce a selective relaxation of the ureteral smooth muscle, which could inhibit the ureteral spasms and result in dilatation of the ureteral lumen and passage of ureteric stones.[1]

\section{MATERIALS AND METHODS}

We conducted a randomised, open label study in a tertiary medical college and hospital during the period from January 2015 to June 2016. The study protocol was approved by our Hospital Research and Ethics Committee.

All patients provided an informed written consent for participation. By convenience 70 patients were enrolled into the study with 35 in each group. No sample size calculation was done. Patients enrolled in this study were 20 years of age and above. They voluntarily decided to take part in this study and gave their written consent. All patients were having lower ureteral calculi of size $\leq 10 \mathrm{~mm}$ on ultrasonography. Patients with blood creatinine levels more than $2 \mathrm{mg} / \mathrm{dL}$, history of drug allergy, pregnant women or nursing mothers were excluded. A thorough clinical examination was done by 
a qualified urologist for all patients. The patients were evaluated by an ultrasonography and x-ray KUB. Simple randomisation by lot method was done to allot patients alternatively into Tamsulosin and Silodosin groups $(n=35$ in each group). The patients from Tamsulosin group were given tamsulosin $0.4 \mathrm{mg} /$ day and the other group silodosin 8 $\mathrm{mg} /$ day single dose at night. The patients were treated for a maximum period of 4 weeks and observed for stone expulsion. The follow-up continued until the patients were rendered stone-free by intervention or spontaneous stone expulsion, as was confirmed by the patient for a maximum of 4 weeks. The primary outcome was the stone expulsion rate and the secondary outcome was the stone expulsion time. Stone expulsion rate was defined as number of patients out of total patients enrolled in the study, who had passed stones after taking drugs for less than or equal to 4 weeks. Time for stone passage was defined as the number of days from the date of study enrolment to the date when patients identified their stone passage or the date of the follow-up visit when the imaging study no longer detected a visible stone. Follow-up was done weekly or at two weeks interval. Data such as demographic data, duration of intake of drugs and time taken for the expulsion of stone were recorded in a specially designed proforma, which was transformed to a master chart and then subjected to statistical analysis. SPSS version 20 software was used for statistical analysis. Statistical analysis was done by using chi-square test, Fisher exact test for qualitative data and student's ' $\mathrm{t}$ ' test for quantitative data like stone expulsion time.

\section{RESULTS}

A total of 70 patients were enrolled in the study. Out of 70 patients, 54 patients completed the study. 8 patients from group tamsulosin and 7 patients from group silodosin were lost for followup. Group tamsulosin (27 patients) consisted of 16 men and 11 women (mean age: $34.8+12.7$ years), group silodosin (28 patients) consisted of 16 men and 12 women (mean age: $36.4 \pm 12.7$ years). There were no statistically significant differences between the 2 groups in terms of sex, age or stone size $(\mathrm{p}>0.05)$.

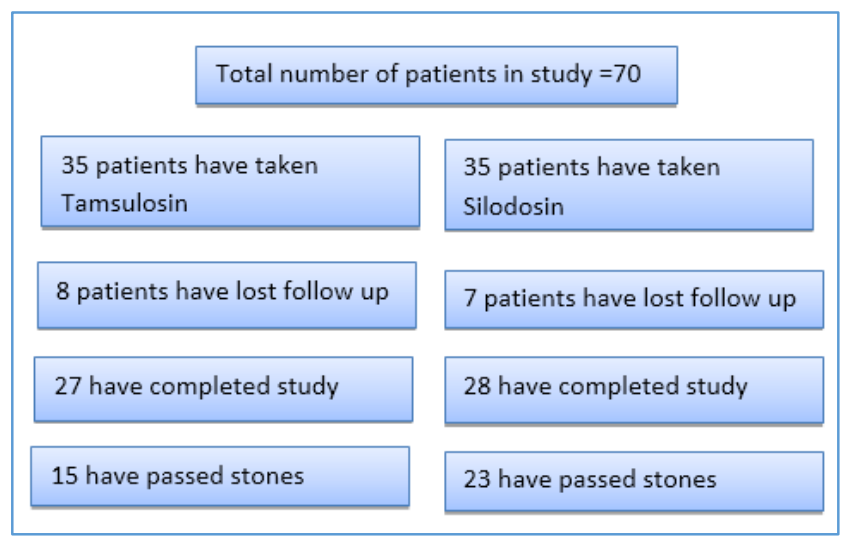

Figure 1. Consort Diagram of Tamsulosin Group and Silodosin Group

The results of the data analysis showed that 15 out of 27 cases in group Tamsulosin and 23 out of 28 cases in group Silodosin had expelled the stones by the end of the study. (Figures 1, 2). The mean time of expulsion in Tamsulosin group was $19.1+8.6$ days, while in silodosin group was 16.7
+6.8 days, $(\mathrm{p}$ value $=0.26$ ). The mean time of expulsion was thus lower in the Silodosin group compared to the Tamsulosin group, but there was no statistical significant association as analysed by the student's ' $t$ ' test, $(p>0.05)$. The difference between the tamsulosin and silodosin did not reach statistical significance (Figure 3).

Expulsion rate in Tamsulosin group was 55.5\%, while in Silodosin group was $82.1 \%$, ( $p$ value $=0.04$ ) which was statistically significant. The relation between stone expulsion and drug used had a significant association. Silodosin faired better in expulsion rate as analysed by Chi-square test, $(\mathrm{p}<$ $0.05)$. No side effects that required cessation of treatment were encountered. Patients were prescribed $50 \mathrm{mg}$ of diclofenac tablets to take whenever required for pain up to a maximum dose of $100 \mathrm{mg}$ and advised to report to us in case of unbearable pain.

Our study showed that in Tamsulosin group, out of 16 male patients 8 had passed stones and out of 11 female patients 7 had passed stones. In silodosin group, out of 16 male patients 13 had passed stones and out of 12 female patients 10 had passed stones, which was statistically not significant (Figures 4,5). Tamsulosin and silodosin group with stone size $\leq 7 \mathrm{~mm}$ did not show a significant difference in stone expulsion rate $(\mathrm{p}$ value $=1)$, whereas $>7 \mathrm{~mm}$ achieved statistical significance ( $p$ value $=0.01$ )

As the life-time risk of developing urinary calculi is between $5 \%$ - $12 \%$, affecting men more than women, ${ }^{[1]}$ so our study has compared if outcome of drugs is affected by gender of patients. The outcome of tamsulosin and silodosin was found to be not affected by gender of patients.

\begin{tabular}{|c|c|c|}
\hline & $\begin{array}{c}\text { No. of Patients } \\
\text { Passed Stones }\end{array}$ & $\begin{array}{c}\text { No. of Patients not } \\
\text { Passed Stones }\end{array}$ \\
\hline Male & 8 & 8 \\
\hline Female & 7 & 4 \\
\hline \multicolumn{2}{|c|}{ P value (Fisher exact test) $=0.69$} \\
\hline \multicolumn{2}{|c|}{ Table 1. Comparison of Outcome of Tamsulosin } \\
according to Gender
\end{tabular}

\begin{tabular}{|c|c|c|}
\hline & $\begin{array}{c}\text { No. of Patients } \\
\text { Passed Stones }\end{array}$ & $\begin{array}{c}\text { No. of Patients not } \\
\text { Passed Stones }\end{array}$ \\
\hline Male & 13 & 3 \\
\hline Female & 10 & 2 \\
\hline \multicolumn{2}{|c|}{ P value (Fisher exact test= 1) } \\
\hline \multicolumn{2}{|c|}{ Table 2. Comparison of Outcome of Silodosin } \\
according to Gender \\
\hline
\end{tabular}

\begin{tabular}{|c|c|c|c|c|c|}
\hline \multirow{2}{*}{ Characteristics } & \multicolumn{2}{|c|}{ Tamsulosin } & \multicolumn{2}{|c|}{ Silodosin } & \multirow{2}{*}{ P-valuec } \\
\cline { 2 - 5 } Sex & No. & $\%$ & No. & $\%$ & \\
Male & 21 & 60.0 & 18 & 51.4 & .47 \\
Female & 14 & 40.0 & 17 & 48.6 & p-value \\
\hline Characteristics & Mean & SD & Mean & SD & .85 \\
\hline Age (In Years) & 34.8 & 12.7 & 36.4 & 12.7 & 0.04 \\
\hline $\begin{array}{c}\text { Stone Expulsion } \\
\text { Rate } \\
\text { (Percentage) }\end{array}$ & $55.5 \%$ & $82.1 \%$ & $\begin{array}{c}\text { (by applying } \\
\text { chi-square } \\
\text { test) }\end{array}$ \\
\hline $\begin{array}{c}\text { Stone Expulsion } \\
\text { Time (Days) }\end{array}$ & $19.1+8.6$ & $16.7+6.8$ & $\begin{array}{c}0.26 \\
\text { (by applying } \\
\text { student's 'T' } \\
\text { test) }\end{array}$ \\
\hline \multicolumn{7}{|c|}{$\begin{array}{c}\text { Table 3. Demographic Details of Patients, } \\
\text { Stone Expulsion Rate and Time }\end{array}$} \\
\hline
\end{tabular}




\section{DISCUSSION}

Urolithiasis is common in the global population, affecting $1 \%$ - $5 \%$ of the population in Asia, 5\% - 9\% in Europe, $13 \%$ in North America and 20\% in Saudi Arabia.[9] Small ureteric calculi have higher probability to pass and do not often need surgical intervention. The most important factors in predicting the likelihood of spontaneous stone passage are stone location and stone size. Ureteral stones account for approximately $20 \%$ of urolithiasis cases; approximately $70 \%$ of ureteral stones are located in the lower third part of the ureter and are known as "distal ureteric stones."[10] Spontaneous passage depends on stone size, shape, location and associated ureteral oedema.[11]

Recently, $\alpha$-blockers used as MET have replaced minimally invasive procedures as the first line of management for small ureteric stones. The most commonly used $\alpha$-blocker for MET is tamsulosin, but similar effects have been shown by other $\alpha$-blockers such as terazosin and doxazosin indicating a possible class effect.[12] There has been a significant improvement in the medical management of the ureteral calculi with the introduction of effective medical therapeutic agents in the market.[13] The $\alpha 1 \mathrm{~A}$ - and $\alpha 1 \mathrm{D}$ adrenoceptors are the most abundant sub-types in the distal ureter; stimulation of these $\alpha 1$ adrenoceptors leads to increase in both the frequency of ureteric peristalsis and the force of ureteric contractions. However, blockade of these receptors decreases basal ureteric tone, peristaltic frequency and amplitude, leading to a decrease in the intraluminal pressure, while the rate of urine transport increases and thus increasing the chance of stone passage. ${ }^{[14,15]}$ Highly selective a1A-adrenoceptor blockers have been developed to minimise the cardiovascular adverse effects, whereas the affinity of silodosin to $\alpha 1 \mathrm{~A}-\mathrm{AR}$ subtype is about 162 -fold and 50 -fold greater than its affinity to $\alpha 1 \mathrm{~B}$ - and $\alpha 1 \mathrm{D}-\mathrm{AR}$ subtypes.

Alpha blockers are thus recommended by the American Urological Association (AUA) and the European Association of Urology (EAU) for MET of distal ureteral stones less than $10 \mathrm{~mm}$ in diameter.[16,17]

In our study, the stone clearance rate was significantly higher in the silodosin group when compared with tamsulosin group at $82.1 \%$ and $55.5 \%$, respectively $(p=0.04)$. Our results were in agreement with those of Gupta and co-researchers, who reported stone clearance rates of $82 \%$ and $58 \%$ for silodosin and tamsulosin groups respectively; and also in agreement with those of Kumar and co-researchers who reported stone clearance rates of $83.3 \%$ and $64.4 \%$ for their silodosin and tamsulosin groups respectively. However, Imperatore and co-researchers reported a non-significant difference of stone clearance rates between silodosin (88\%) and tamsulosin (84\%).

In our study, stone expulsion rate was calculated for stone size $\leq 7 \mathrm{~mm}$ and $>7 \mathrm{~mm}$ size. In our study, stone expulsion rate was not significant between silodosin and tamsulosin group with stone size $\leq 7 \mathrm{~mm}$, but stone size $>7 \mathrm{~mm}$ showed statistical significance. Also, the mean (SD) stone expulsion time was shorter in the silodosin group vs the tamsulosin group at 16.7 (6.8) vs 19.1 (8.6) days, but could not reach statistical significance.

These results are also in agreement with those of Gupta and co-researchers, who also reported significantly shorter mean (SD) stone expulsion times in the silodosin vs the tamsulosin group at 12.5 (3.5) vs 19.5 (7.5) days, respectively; and also in agreement with Kumar and coresearchers who reported mean (SD) stone expulsion times of 16.5 (4.6) days in the tamsulosin group and 14.8 (3.3) days in the silodosin group. However, Imperatore and coresearchers reported a shorter mean stone expulsion time for both silodosin and tamsulosin of 6.7 and 6.5 days, respectively.

In our study, no significant difference was observed in the outcome of tamsulosin and silodosin with respect to gender of patients. Our study had some limitations. Adverse effects of tamsulosin and silodosin such as headache, hypotension and retrograde ejaculation were not compared in our study.

\section{CONCLUSION}

We found that silodosin was more effective for distal ureteric calculi of size $>7 \mathrm{~mm}$ size. We conclude that silodosin is better than tamsulosin in terms of stone clearance rate and stone clearance time for the management of distal ureteric calculi of size $<10 \mathrm{~mm}$. We recommend that a conservative approach should be considered as an option in the management of the uncomplicated, small, distal ureteral calculi. Large multicentre trials are required to prove the efficacy and safety of silodosin over tamsulosin.

\section{REFERENCES}

[1] Smith RD, Shah M, Patel A. Recent advances in management of ureteral calculi. F1000 Med Reports 2009;1:53.

[2] Imperatore V, Fusco F, Creta $M$, et al. Medical expulsive therapy for distal ureteric stones: tamsulosin versus silodosin. Archivio Italiano di Urologiae Andrologia 2014;86(2):103-7.

[3] Porpiglia F, Destefanis P, Fiori C, et al. Effectiveness of nifedipine and deflazacort in the management of distal ureter stones. Urology 2000;56(4):579-82.

[4] Tzortzis V, Mamoulakis C, Rioja J, et al. Medical expulsive therapy for distal ureteral stones. Drugs 2009;69(6):677-92.

[5] Seitz C, Liatsikos E, Porpiglia F, et al. Medical therapy to facilitate the passage of stones: what is the evidence? Eur Urol 2009;56(3):455-71.

[6] Autorino R, De Sio M, Damiano R, et al. The use of tamsulosin in the medical treatment of ureteral calculi: where do we stand? Urol Res 2005;33(6): 460-4.

[7] Borghi L, Meschi T, Amato F, et al. Nifedipine and methylprednisolone in facilitating ureteral stone passage: a randomized, double-blind, placebocontrolled study. J Urol 1994;152(4):1095-8.

[8] Sasaki S, Tomiyama Y, Kobayashi S, et al. Characterization of a1-adrenoceptor subtypes mediating contraction in human isolated ureters. Urology 2011;77(3):762.e13-7.

[9] Ramello A, Vitale C, Marangella M. Epidemiology of nephrolithiasis. J Nephrol 2000;13(Suppl 3):S45-S50.

[10] Erturhan S, Erbagci A, Yagci F, et al. Comparative evaluation of efficacy of use of tamsulosin and/or tolterodine for medical treatment of distal ureteral stones. Memorial Hospital, Istanbul, Turkey. Urology 2007;69(4):633-6. 
[11] Coll DM, Varanelli MJ, Smith RC. Relationship of spontaneous passage of ureteral calculi to stone size and location as revealed by unenhanced helical CT. AJR Am J Roentgenol 2002;178(1):101-3.

[12] Türk C, Knoll T, Petrik A, et al. Guidelines on urolithiasis. In: EAU guidelines, presented at the 29th EAU annual congress, Stockholm 2014.

[13] Cervellin G, Comelli I, Comelli D, et al. Regional shortterm climate variations influence on the number of visitsfor renal colic in a large urban emergency department: results of a 7-year survey. Internal and Emergency Medicine 2011;6(2):141-7.

[14] Griwan MS, Singh SK, Paul H, et al. The efficacy of tamsulosin in lower ureteral calculi. Urol Ann 2010;2(2):63-6.
[15] Rossi M, Roumegue 're T. Silodosin in the treatment of benign prostatic hyperplasia. Drug Des Dev Ther 2010;4:291-7.

[16] Tiselius HG, Ackermann D, Alken P. Guidelines on urolithiasis. European Association of Urology 2000. http://www.uroweb.org/fileadmin/user_upload/Guid elines/Urolithiasis.pdf (last accessed on 2014).

[17] Management of ureteral calculi: EAU/AUA nephrolithiasis panel. American Urological Association 2007.

http://www.auanet.org/education/guidelines/ureter al-calculi.cfm (last accessed on January 29, 2014). 